\title{
Text and Image of Advertising in Nigeria: An Enterprise of Socio-Cultural Reproduction
}

\author{
Taofeek Dalamu \\ Department of English, University of Lagos, Akoka, Yaba, Nigeria \\ E-mail: lifegaters@yahoo.com
}

Doi:10.7575/aiac.alls.v.7n.6p.197

Received: 18/09/2016

URL: http://dx.doi.org/10.7575/aiac.alls.v.7n.6p.197

Accepted: 22/11/2016

\begin{abstract}
The role of language in the construction of socio-cultural reality is inevitable. That is why text is used as a pillar that supports the explication of the intended purpose of images applied in multifaceted ad plates. It is a phenomenal tradition that has remained strong in ad campaigns. Advertisers make images and text as discrete components that are inseparable. Images and texts are sedimentary devices in ads, which we can consider as the social position that motivates this enquiry. After the selection of ten ads from various social strata, semiotics viewed from the stances of Saussure and Peirce has been applied along with social semiotics to analyze the ads. The study reveals that ads and advertisers are keen to the promotion of culture with the use of images with textual collaboration. Reference to antiquity has been exposed as a very useful material in ads because it fascinates the public by reproducing their about-to-beforgotten cultural heritage. Social exercises in the ads create side attractions that lead to assorted photographic entertainment. Besides boosting the audience social knowledge, socio-cultural reproduction experienced in ads can propel the concerned agencies to repackage our cultural beauties as a means of economic growth and emancipation.
\end{abstract}

Keywords: Advertising, Consumer, Language Function, Social System, Semiotics

\section{Introduction}

Advertising is meant for the society; the society is meant for advertising. The former assertion dominates professional focus while the later indicates professional material. Advertising creates a link, an unremarkable link indeed, between a product and the entire public. A bond of affinity and subsistence are not only created but also sustained so that the loyalty of the consumers is consistently mechanized for the betterment of products' manufacturers. In that wise, the focus of advertisers seems to be more on the society and less on the products. The content of the product has certain qualities. The internalized qualities are the nugget of their campaigns knowing well that consumers may not be aware of those qualities. Advertisers present the products to intended customers and as much as possible want the consumers to believe the rhetoric and logic of their objectives. Given to that circumstance, advertisers attempt all possibilities with their semiotic, ideological, discourse strengths to craft messages that can compel the audience to surrender to the ad's claim. Advertisers, as professionals, focus the society and calculate modalities on how to convince them to patronize certain goods and services.

Professional focus serves as a stimulant to professional material. The society, as the target audience, needs to be convinced before they purchase any good or service. Perhaps, advertisers understand that it might be difficult to separate the society (the people) from their environmental phenomena, hence, their adoption. Advertisers keenly attempt to look inward into the society in search of materials that can easily convince them to listen to their discourses the ads. By society, the study refers to all domains of human operational activities on earth including waters, sky and space. Another focal point as far as the society is concerned is the involvement of people in cultural emancipations, language applications, behavioral exercises, thoughts, modes of education, political systems, religious beliefs, professions, etc. The observation of human social activities, the selection of a particular aspect of the social norms and the inculcation of the social standard into advertising are referred to as socio-cultural reproduction. As a reliable strategy, advertisers borrow and adopt meaningful elements in the societal space to campaign their products to the society. The implication could be replicated thus: the product is manufactured from the society, behaves as a device of the society and for the society. At all cost, the product is organized in such a way that will make it to forcefully socialize with the society. Therefore, socio-cultural reproduction becomes an endless revolution and a constant crusade that advertisers cannot do without. That is the remark that motivates this enquiry. The study explains the socio-cultural reproduction in ads not only as a norm but also as a persistent business value that revolves around advertising proliferation in Nigeria.

\subsection{Advertising, Social System and Conceptual Reproduction}

The genre of advertising does not operate in isolation of a social system for it to be reified. The social system and structure dictate to a considerable extent, the direction that a product's ad in a particular society is constructed and construed. If the intention of advertising is to inform as well as persuade the public, then it should not be produced out 
of the socio-cultural domains of the audience. The social structure-cum-system goes a long way in shaping ads so that the audience can easily perceive and digest the message without any ambiguous representation. Ad and social system must be potentially symmetrical and complementary. Social structure (interchangeably used as social system), in which ads functions, has been explained as 'a concern with the structured social relations which comprise organization and occupational practice and the institutional sector with which they are regularly identified' (Scheloff 2006:87). Schegloff expatiates that the social structure dominates population distribution in terms of power, resources desirables, individualized statuses and roles, ethnicity, age, gender, education, profession, origin, language, culture, religion, etc. The presence and relationship of the interactions of these elements constitute the systematic operations in the society.

Every human social system involves in the complex shared beliefs. In a single social environment, the complexity of their beliefs can be observed in the way that they are culturally entwined. A social system, irrespective of its human strengths, accommodates several sub-systems that allow other beliefs to thrive. The intertwining of different beliefs from a general perspective, that is, broad and narrow perspectives observed in the sub-system of the social sphere positions the entire social system as complex. The social system might most times be the constructs of human beings or/and perhaps, of nature. Irrespective of the creator of the social, it is conceived in terms of tribes, classes, associations, etc. and having individuals as its circumstantial products, principal actors and heroic elements. This opinion has rightly been supported in Beck \& Beck-Gernsheim (1996) who posit that "the social has almost always been conceived in terms of tribes, religions, ... and above all recently, of social system. The individuals are the interchangeable elements, the product of circumstances. The character marks, the subjective factor... the indefinable" (Beck \& Beck-Germsheim 1996:40). Human beings activate the social system because both the natural and artificial phenomena are built around them. A system collapses when the individuals are taken away from it or perhaps, refuse to perform their roles. The subjective complexity of an individual can be experienced in so many forms which include his link with the central social system and sub-systems, and when he moves out from the current socio-cultural system to different system. All these portray the nature of the individual in the social system that poses constraints to its concise description.

Notwithstanding of the complexity of human beings in a social structure, the functions of language cannot be undermined. It is a communicative facility that permits the central social and sub-social system to properly operate. It weave them in functional harmony. Language or languaging, as it were, permeates through the fabric of the sociocultural network to get things done as desired. It is based on the centrality of language to the social structure and human existence that Jakobson (2006) introduces six functions of textual communications to demonstrate how language is leverage as an exchange of referential information. Jakobson's advocacy on ways in which language functions in the society at its best is enumerated thus: language is expressive (emotive); language is informative (referential); language is vocative (conative); language is phatic (interactional); language is aesthetic (poetic); and language is metalingual (metasemiotic/metacode/conceptual/theoretical) (See www.dipartimentolingue.unito.it/herrmann/documents/; Jaworski \& Coupland 2006:41). These logical offerings are a demonstrator of a statement that no one can easily successfully discard with a wave of hand the role of language in society.

By anchoring the thought of Jakobson on language functions from its metalingual hooks, it could be interpreted that language is the collections of arbitrary representations. Sometimes, the recognition needed to interpret meaning from the arbitrary icons is achieved through socio-cultural relations of users. It then means that it is not everyone who listens to, or reads a particular language is really capable of making meaning out of the language in use. A language of communicative operation is probably making meaning to those who (sometimes) are oriented in the societal culture of the owners of the language. Besides, the argument of Jakobson is still rested on the notion of language containing conceptual terms that demand explanations. The descriptions of the concepts might become a herculean task without reliable theories that could assist to elucidate them. In that sense, language does function as a facility for explaining itself. Language is employed to explain language. The claim has been observed over the years where linguists (and sometimes philosophers) employ phonological, grammatical, clausal, semantic, etc. imports to scrutinize the language itself. For instance, (Halliday and Matthiessen 1997:1-6) discuss a link between grammar and grammatics where a theory of grammar is a tool for analyzing the nitty-gritty of grammar itself.

Perhaps, linguists have been held into Jakobson's highlighted functions for decades; and as much their validity nowadays is still incontrovertible. This persuades Hébert (2011) to further summarize the Jakobsonian functions of language that:

* The referential function is oriented towards the context, which he argues to be the dominant function in a communication. The core of the informative text provides the knowledge about the topic of the discourse.

* The emotive function is oriented in the direction of the addresser, which occurs as interjections in the message. This indicates the participant's expression of feelings, attitudes and opinions.

* The conative function is oriented toward the addressee, which is seen as imperatives and apostrophes. In this case, language is used to produce certain effect on the target audience. The audience is textually induced and mobilized to feel or act in a particular way.

* The phatic function serves to establish, prolong or discontinue communication or confirm whether the contact is still intact.

* The metalingual function establishes mutual agreement on the code, which may be salient. Language functions in this provincial orb to query issues and at the same time explain matters.

* The poetic function puts the focus of the text of the message for its own sake (Hébert 2011: 1). 


\subsubsection{Language communicative parameters}

Jakobson's argument does not only create a connection between linguistics and poetics; it also lays a significant foundation for the functions of language in general as exhibited by users in society. However, it is reported that the Hallidayan systemic functional approach of addressers and audience interaction taps its currency from Jakobson's thoughts (Jaworski and Coupland 2006:41). In systemic functional linguistics (SFL) the utmost reason of communication is to interact with others in other to establish and maintain indivisible social relationships (Thompson 2004:45). The claim is obvious in conversation and other forms of communicative interaction that in one way or another receive feedback. It is explained in SFL that language should not be viewed as a one-way system as long as meaning is exchanged in the goings-on. Good examples of one-way system of communication that resort in interactions are advertisements and invitation cards (Awonusi 2007:86). The addresser and addresses enter into a communicative exchange that is resourceful. They decode meaning potential from the text.

Users deploy the instrumentality of language to make order, to apologize, take excuse, make a request, praise people, reject offers, confirm deals, castigate, analyze events, etc. From a classificatory point of view, Halliday (1994) suggests a range of fundamental types of exchanges celebrated as speech roles. He recognizes them as: giving information; demanding information; giving goods-\&-services and demanding goods-\&-services. The four systemic resources are labeled as offer, statement, command and question. Giving and demanding information perform a constitutive function in a social system while giving and demanding goods-services explore ancillary communicative functions in relationship building (Halliday 1994:68-71; Halliday \& Matthiessen 2004:106-111). The linguistic-poetic approach of Jakobson lays a solid foundation for functions of language; and the systemic-linguistic thought might be classified as an extension of the Jakobsonian idea. The approaches demonstrate the inevitability of language in every social system and structure.

Advertisers, having been armed with the relationship between language and society, organize our experience in the social system in a critically significant model to influence the audience. This is parallel with the thought of Dijk that advertising is socially invented and reproduced for social consumption (van Dijk 1988:135). Advertisers select aspects of events in the society to avoid unusual arbitrariness that may create confusion or ambiguity. Using a strange object in ad campaigns could be complex for consumers' understanding. The resultant effect of such practice on the product may perhaps be enormous and portray a negative signal. Human beings easily decipher meaning from commonly familial objects experienced in the society. Familiarity of consumers with a created social event produces a similar identity between the products and elements in the society that are already settled in the sub-conscious of consumers. The 'systemic coherence' - to adopt the formulation of Luhman (1996:60) - of the societal value with product is an unmarked conduct that can quickly connect the desires of advertisers with the consumers'. The chance is that formations of advertising communications out of the existing social communicative value to sell a product may not likely pose any difficulty in consumers' understanding of the message, but rather influence them.

Goldman (1992) explains advertising as a form of social practice, which Lemke (1995:106) constructs as semiotic cultural abstraction. It relies on the existence of a built environment that presupposes commodified relations in which the world represented in ads appears as the only possibility (Goldman 1992:34, 50,185). The social elements and truths of consumers' immediate contexts are shared as persuasive devices to avert multiple ideological representations that may lead to chaotic interpretations (van Dijk 1988:149-50). In advertising linguistic chemistry, the diversification of conflicting cultural perceptions is avoided as an impediment. Common features of the society are shared in the ad enterprise as much as possible. This seems to be a strategic creative potential that can integrate the product into a common place in society. That could explain why advertising should be seen as an invented and interpretation of a sense of possible reality of the community (Beck \& Beck-Gersheim 1996:45-46).

\subsection{Theoretical Bias}

Although, the universality of Saussure with semiotics has been over-flogged for several decades, we will care to emphasize that a prominent study of semiotics began in earnest with Saussure, the father and founder of semiotics. His thoughts laid a very good foundation for discourses on the subject. Saussure perceives semiotics as a science that studies the life of signs with society (Dyer 2005:115). There is a vital denominator in Saussurean semiology, that is, signification. Signification is conceptualized as the connection that exists between the signifier and the signified (de Beaugrande 1991:8,13). In other words, an object is interpreted through its communicative form to realize the meaning that the society assigns to it.

Since Saussurean semiotic technicality seems to be the appropriate first leg into its exploration, a number of semioticians have contributed to its development in so many forms. Peirce (1931-58) observes semiotics from a philosophical altitude as a doctrine of signs which tends to construct an affinity with logic. In contrast to Saussurean model, Pierce taxonomizes signification into the concept of Representant, Interpretant and Object (Peirce 193158:2.227). Morris approach on semiotics is in consonance with Saussure's. He perceives semiotics as the science for signs (1938:1-2). Eco Umberto (1976) suggests that semiotics is duly concerned with everything that can be taken as sign (Eco 1976:7). Apart from the classificatory models propagated in structuralism and logical approaches, they have the concept of sign - something that stands to somebody for something else in some respect or capacity (Williamson 1978:20) - as a unifying device in semiology that aims to appreciate any system of signs in an analytical form (Bathes 1967:9). The notion of signifier and signified is also vibrant. 
Saussure offers a clear description on how a system of signs work by predicating on what he calls the signifier and the signified being the distinct parts of a sign. The signifier is the perceived object, that is, the material vehicle or form which the signified is the referent, that is, the mental concept or conceptual representation (Williamson 1978:20; Dyer 2005:118). There are signifiers that have universal conceptualization. However, the signifiers are usually acculturated. The culture of a particular society provides meaning to a particular signifier. For example, the way a signifier is signified in Yorùbá might be different from the way it is signified in English. Àga or àpótí in Yorùbá is chair in English. Signification connects us to the concept of arbitrariness of a sign system. It is explained that 'A signifier has potential but not actual meaning whereas the signified is the meaning which the signifiers refers to' (Ibid.). The socio-cultural knowledge of the society unlocks the potential meaning of a signifier. So, the relationship that exists between the signifier and the signified is unraveled through social and cultural conventions.

The inevitability of Saussurean coinages of the signifier and the signified is further observed in Peircean triadic model of signification. According to Peirce Sanders, there are three distinctions in a system of signs. The distinctions are conceptualized as iconicity, indexicality and symbolicity. Having propagated a system of signs as the heart of every communicative element, Peirce argues that the signifier-signified idea should be characterized into the domains of icon, index and symbol. Iconicity represents a visual perception where the signifier resembles the signified. This type of imitative recognition is observed in human beings and photos, tastes and beverages. For instance, the characteristics of Cocacola ${ }^{\circledR}$ taste is different from Pepsi ${ }^{\circledR}$ taste whereas both beverages are soft drinks; also the taste of Gulder $^{\circledR}$ is dissimilar from that of Harp ${ }^{\circledR}$ despite that both of them are a family of lager beer. Sounds also have the attribute of iconicity. Juju music, fuji music, apala music (genres of music in Nigeria) and hip hop music are differentiated through their unparalleled sounds. The sound parameters of a Nissan ${ }^{\circledR}$ car are special from that of a Honda ${ }^{\circledR}$ car. Indexical signification indicates a social situation where the signifier relates to the signified in a direct and perhaps professional correlation. Inferences can be generated from their relationship.

Professional kits are categorized as indexical. Caterer dresses, doctor laboratory coats, engineer overalls, lawyer gowns, doctorate gowns and theatrical costumes in Nigerian films illustrate indexicality of signifier-signified relationships. For an object to be symbolically meaningful, the signifier is not perceived as resembling the signified. It implies that arbitrariness of the meaning of an object connotes social conventions. Such a social phenomenon is learnt according to rules of the society e.g. rose as a representative of love, alphabet and language, traffic lights and motoring, national flags, logos and anthems, mechanical accuracy in writings. It is worth to note that sometimes indexical and symbolic sign systems do overlap. Chandler (1994:22-28) and Dyer (2005:124-126) illustrate and expatiate details of Peircean semiotics.

\subsubsection{Semiotics as a meaning-making facility}

In recent times, semiotics exploration has become increasingly less Saussurean and Peircean. There is a critical shift from old to new ideas. The classifications of signification have been migrated to the examination of the production modes of signs and codes, their applications, transformations, etc. in the social system. That is why Blommaert (2005) notes from the perspective of discourse that semiotics is a meaningful symbolic behavior in a social practice (Blommaert 2005:2). In support of Blommaert, it is explained that 'contemporary social semiotics have move beyond structuralism to investigate the use of sign in a specific social context and circumstance (Chandler 1994:2). Semiotics has been advanced to cultural studies and ideology as demonstrated in Bathes' Mythologies (1957), van Dijk's Ideology (1988) and Lemke's Textual Politics (1995). In a scholarly confession, Hodge \& Kress (1988) say a fascinating piece about semiotics that it offers the promise of systematic, comprehensive and coherent study of communication phenomena as a whole, not just instances of it (Hodge \& Kress 1988:1). A comprehensive aspiration on the arms of semiotics is important for a 'full' understanding of its applicable capability. Those appendages have potential to reveal how objects communicate in a particular social sphere. Then, it can create a robust cultural awareness and expose cultural values of the social system to the audience.

The diversity of semiotics is also recognized in SFL where Halliday and Matthiessen explain semiotics as a meaningmaking resource of the matrix of lexico-grammar (Halliday \& Matthiessen 2004:62) of language that possesses meaning potential. This stance provides a link to the functional-rank matrix in the grammar of English. Ravelli (2000) confirms the grammatical functional-rank system as morpheme, word, group/phrase and clause; and identifies the clause as the hub of grammatical investigations (Ravelli 2000: 29, 31). Given to this grammatical circumference, the verbal sign systems in advertising (the chosen data) is analyzed through the view of Bloor \& Bloor (2004) on the clause structures. According to them, the elements that construct the clause are: Subject (S), Finite (F), Predicator (P), Complements - direct object $\left(\mathrm{C}^{\mathrm{do}}\right)$, indirect object $\left(\mathrm{C}^{\text {ind }}\right)$, intensive $\left(\mathrm{C}^{\text {int }}\right)$ and Adjuncts - circumstantial $\left(\mathrm{A}^{\text {cir }}\right)$, conjunctive $\left(\mathrm{C}^{\text {con }}\right)$ and modal $\left(\mathrm{C}^{\mathrm{mod}}\right)$. The five clause semiotic addresses are simply recapitulated as SFPCA (Bloor \& Bloor 2004;38-59). The domain of social semiotics could be recapped with the opinion of Lemke who describes the subject as 'the general study of meaning-making (semiosis), ... meanings we make with language, ...meanings we make with every sort of object, event or action in so far as it is endowed with a significant, a symbolic value, in our community (Lemke 1995:9). Natural and artificial objects that are available in the social system could be analyzed in context with assets of its social practices.

\section{Methodology}

The sites of our data gathering are the newspaper and signpost. The newspaper (e.g. The Punch) is chosen because it is the custodian of most of the print ads in Nigeria. The presentation of data is somehow erratic; the ads are presented in the Discussion section so that the readers can easily perceive the concerned ad that we are explaining in the moment. 
The concept of signification in semiotics has been applied to the analysis of images in the ad plates. Meanwhile, the analysis of text follows the Hallidayan structural thoughts propagated in Bloor and Bloor (2004) as SFPCA along with the Piercean semiotic triadic concepts as explained in Dyer (2005). The dual approaches - signification and social semiotics - are adopted to provide harmonious and an exclusive analysis of elements - images and texts - in the ads.

\subsection{Data Analysis}

PL1

\begin{tabular}{|l|l|l|l|}
\hline \multirow{2}{*}{ IMAGE } & Social Representation & Signification & Remark \\
\cline { 2 - 3 } & Antiquity & iconic & The three statutes resemble human beings \\
\hline \multirow{2}{*}{ TEXT } & Celebrate & your Orijin & \multicolumn{1}{|c|}{} \\
\cline { 2 - 3 } & P & C & \multicolumn{2}{|l}{} \\
\cline { 2 - 3 }
\end{tabular}

PL2

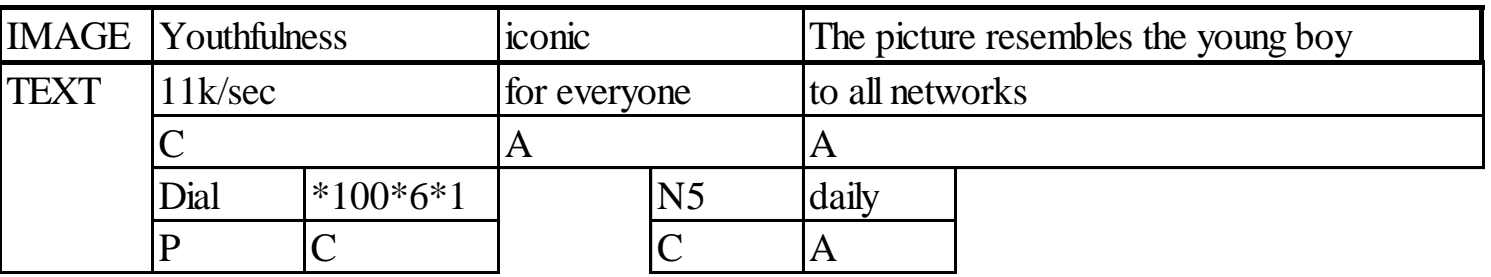

PL3

\begin{tabular}{|l|l|l|l|l|}
\hline IMAGE & Judge & indexical & The image \\
\hline \multirow{2}{*}{ TEXT } & Malaria & remins esentenced & in LONART custody \\
\cline { 2 - 4 } & $\mathrm{S}$ & F/P & A \\
\hline
\end{tabular}

\begin{tabular}{l|l|l|l|} 
PL4 IMAGE & Family & iconic & The photo contains a father and children \\
\hline
\end{tabular}

\begin{tabular}{|c|c|c|c|c|}
\hline \multirow[t]{4}{*}{ TEXT } & Seize & greater value & \multicolumn{2}{|c|}{ for your money } \\
\hline & $\mathrm{P}$ & $\mathrm{C}$ & A & \\
\hline & Save to $\mathrm{pu}$ & smiles & on the faces & of your loved ones \\
\hline & $\mathrm{P}$ & $\mathrm{C}$ & A & A \\
\hline
\end{tabular}

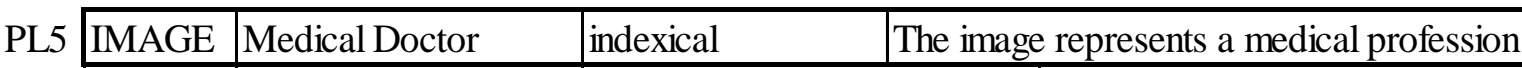

\begin{tabular}{|c|c|c|c|c|}
\hline \multirow[t]{4}{*}{ TEXT } & \multicolumn{2}{|c|}{ Glo health cover } & ... consult & $\begin{array}{l}\text { in over } 8000 \text { accredited hospitals } \\
\text { in Nigeria }\end{array}$ \\
\hline & \multicolumn{2}{|l|}{$\mathrm{C}$} & A & A \\
\hline & Dial & $* 616$ & to register & \\
\hline & $\mathrm{P}$ & $\mathrm{C}$ & $\mathrm{A}$ & \\
\hline
\end{tabular}

\begin{tabular}{|l|l|l|l|l|l|}
\hline PL6 & IMAGE & alcoholic drink & symbolic & \multicolumn{2}{|l|}{ The bottle can represent something else } \\
\hline \multirow{2}{*}{ TEXT } & the spirit & of independence & & Reward & yourself \\
\cline { 2 - 3 } & $\mathrm{C}$ & $\mathrm{A}$ & & $\mathrm{P}$ & $\mathrm{C}$ \\
\hline
\end{tabular}

\begin{tabular}{l|l|l|l|}
\hline PL7 IMAGE & cultural attire & iconic & Signifier is a picture of a Yoruba woman \\
\hline
\end{tabular}

\begin{tabular}{|l|l|l|}
\hline \multirow{2}{*}{ TEXT } & Celebrating & the true Nigerian spirit \\
\cline { 2 - 3 } & $\mathrm{A}$ & $\mathrm{C}$ \\
\hline
\end{tabular}

\begin{tabular}{|l|l|l|l|l|l|}
\cline { 1 - 3 } PL8 & IMAGE & bottle of oil & symbolic & The image does not resemble the signified \\
\hline \multirow{2}{*}{ TEXT } & Celebrating & World Food Day & healthy oil for healthy family \\
\cline { 2 - 4 } & $\mathrm{P}$ & $\mathrm{C}$ & $\mathrm{C}$ & $\mathrm{A}$ \\
\hline
\end{tabular}

Figure 1. Dual semiotic analyses of the ads - Piercean and Hallidayan 
Figures 2 and 3 below characterize the nature of semiotic applications of the ten ads analyzed in Figure 1.

\begin{tabular}{|l|l|l|l|}
\hline Ad & Iconic & Indexical & Symbolic \\
\hline PL1 & 1 & 0 & 0 \\
\hline PL2 & 1 & 0 & 0 \\
\hline PL3 & 0 & 1 & 0 \\
\hline PL4 & 1 & 0 & 0 \\
\hline PL5 & 0 & 1 & 0 \\
\hline PL6 & 0 & 0 & 1 \\
\hline PL7 & 1 & 0 & 0 \\
\hline PL8 & 0 & 0 & 1 \\
\hline PL9 & 1 & 0 & 0 \\
\hline PL10 & 1 & 0 & 0 \\
\hline
\end{tabular}

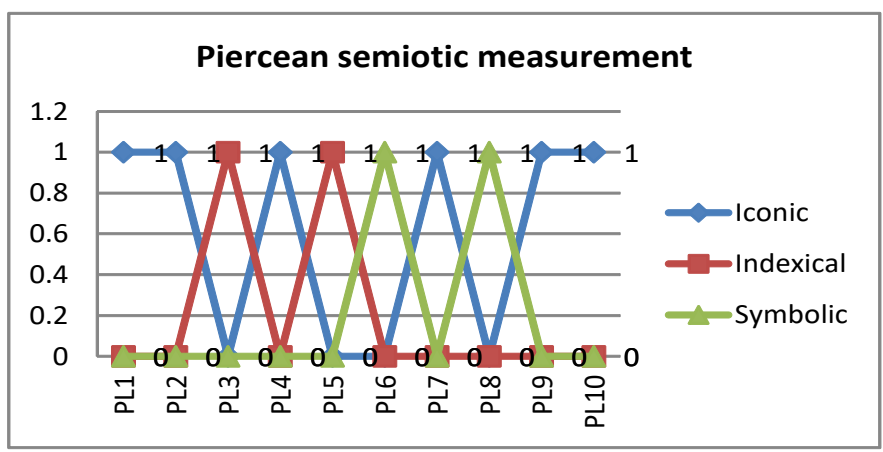

Figure 2. Value representations of the ads in Piercean semiotic analysis

Figure 2 shows that iconic signification dominates the ad campaigns. The values admit that both indexical and symbolic play supportive roles. These are indicators that the application of resemblance objects is a dream in advertising.

\begin{tabular}{|l|l|l|l|l|l|}
\hline Ad & S & F & P & C & A \\
\hline PL1 & 0 & 0 & 1 & 1 & 0 \\
\hline PL2 & 0 & 0 & 1 & 3 & 3 \\
\hline PL3 & 1 & 1 & 1 & 0 & 1 \\
\hline PL4 & 0 & 0 & 2 & 2 & 3 \\
\hline PL5 & 0 & 0 & 1 & 2 & 3 \\
\hline PL6 & 0 & 0 & 1 & 2 & 1 \\
\hline PL7 & 0 & 0 & 0 & 1 & 1 \\
\hline PL8 & 0 & 0 & 1 & 2 & 1 \\
\hline PL9 & 1 & 1 & 0 & 2 & 0 \\
\hline PL10 & 0 & 0 & 1 & 1 & 0 \\
\hline
\end{tabular}

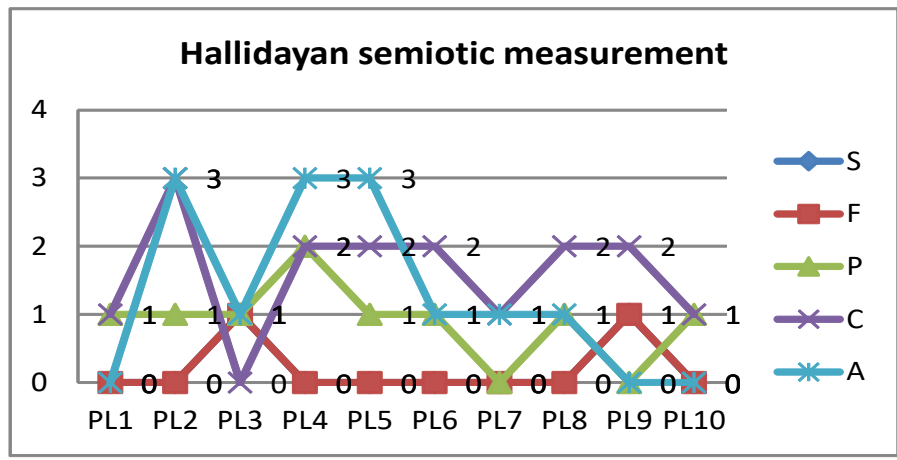

Figure 3. Value representations of the ads in Hallidayan semiotic analysis

Three elements of Complement (C), Adjunct (A) and Predicate (P) function effectively in the ten ads. In the analysis, Subject $(\mathrm{S})$ and Finite $(\mathrm{F})$ play insignificant roles. It reveals that advertising constructs messages more often on noun words.

\section{Results and Discussion}

The explication of the ads analyzed follows the path of Sells and Gonzalez (2002). They observe the components of ads from three distinctive merits. Sells and Gonzalez suggest the three regimental devices as: text, image and organization of elements (Sells and Gonzalez 2002:1-5). Our intellectual standpoint harmonizes image, text and their organization together as a process of the advertisers' conscious decision to persuade the audience.

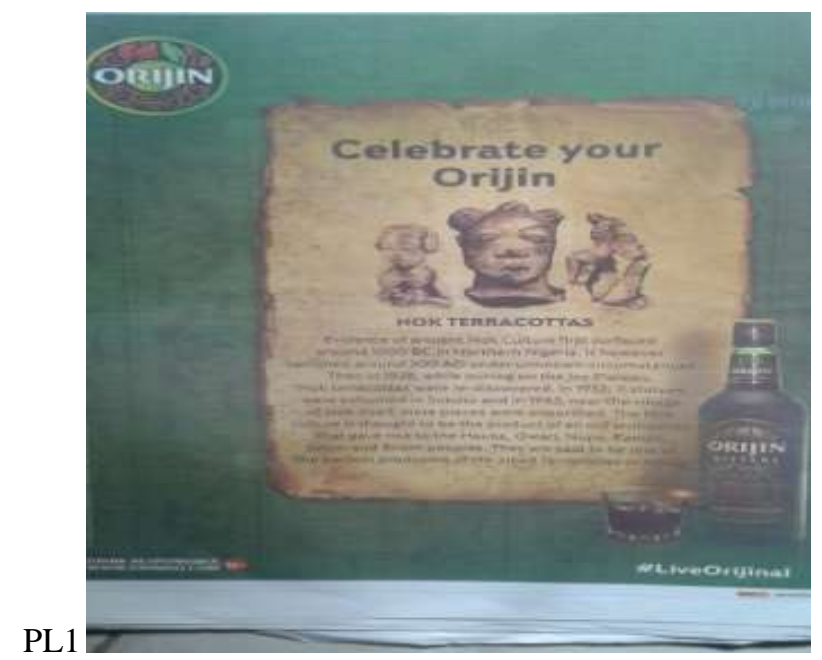

There are three culturally reproduced iconic statutes in the ad of Orijin ${ }^{\circledR}$ in PL1. These are archaeological antiquities that are human pantomimes. Among the three images, a woman occupies the centre position with two supposed young men in both right and left sides. The positioning indicates the importance of a woman at home and society. One is able to differentiate the differences in the images through the platting of their hair styles. The terracotta depict a cultural heritage of the Hausa, Gwari, Nupe, Kanuri, Junkun and Birom people. It is explained in the print ad that evidence of 
ancient Nok culture first surfaced around 1000BC in Northern Nigerian... In 1928, while mining in Jos Plataeu Nok terracotta were rediscovered. ... and in 1943...more pieces were unearthed. They are said to be one of the earliest producers of life-sized terracotta in Africa.

The bold text, Celebrate your orijin, is the main concern of the advertiser. The other text below the terracotta provides a synopsis of the terracotta so that the audience can be passionate to appreciate the historical strength of the advertiser of Orijin for providing such information. It is observed that the bottle of Orijin along with a half-full glass cup is presented to the public. The organization - text, image, product, drinking device - demonstrates that the advertisers is very conscious of his intention to provide persuasive information to consumers. The presentation of the terracotta is not only historically educative but also inductively captivating. However, this is an advertising strategy to communicate to consumers through their original historical past that most of them may not be aware of. And it is the consumption of the Orijin that connects them to their origin. It is worth-noting that the alphabetical letter ' $\mathrm{g}$ ' in origin is phonetically realized as the palatal /j/. The depiction brings a close relationship between the product, Orijin and terracotta as an iconic one. However, the content of Orijin only symbolizes the terracotta.

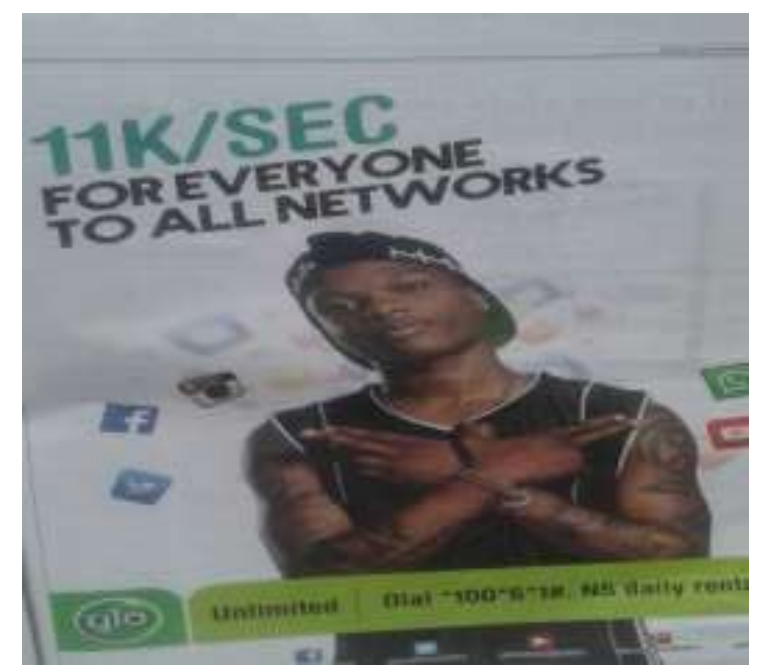

PL2

The Glo ${ }^{\circledR}$ ad in PL2 shows a young chap that occupies almost the entire plate of the ad with inscriptions: $11 \mathrm{k} / \mathrm{sec}$ for everyone to all networks; Dial $* 100 * 6 * 1 * N 5$ daily... The picture is reproduced as a social phenomenon that radiates youthful age. The three elements that transmit youthful exuberance in him are the fez cap, which its truncated cone (fez) is turned to the back, the earring in his left ear, the sleeveless clothe and a shade of tattoos on his arms. The picture indicates iconicity of an object which is a representation of the young boy. Meanwhile, his hands are crossed like the railway crossing textual board with two fingers signaling eleven to further support the written text, $11 \mathrm{k} / \mathrm{sec}$ for everyone to all networks. The boy is a symbol of the youth and as well assists to campaign the message of the ad about the eleven kobo propaganda that the audience need to be cognizant. Using a young chap to publicize the message is a very significant approach; a youth represents a good part of the society and the engine of the society. Besides, a youth possesses enough potency to perform a number of remarkable functions. The youth as an entity of the social system have all the time for virtually everything because they might not be married yet, their time and money will be channeled to a particular direction. Above all, the youth are known for fun of a larger dimension. These orientations might have informed the Glo advertiser to parade the picture of a boy as an iconic representation of youthfulness. The semiotic message of the product and image does not have anything in common, except that the image is an avenue to indicate to the audience $11 \mathrm{k} / \mathrm{sec}$ for everyone. Having understood that the youth are known to be fond of the social media, it is imperative that someone in such age bracket is used for the telecoms message. However, Dial $* 1000 * 6 * 1 *$ does not have any relationship with the image of the boy. It shows the audience the root to benefitting from the package that Glo advertises.

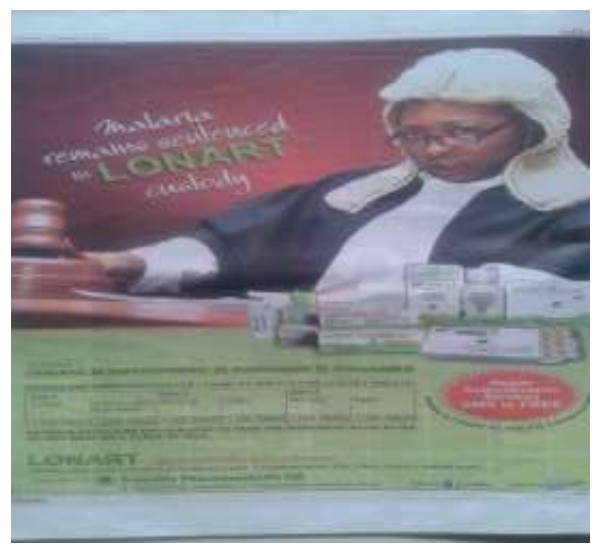


PL3 disguises the image of a judge who gives verdict in the court of law on a particular charge. This social reproduction is indexical because of the resemblance of the image with a professional identity of the judiciary. People regard the judicial arm of the social system as an independent and the hope of a common man. The judge is an arbiter between the people and malarial fever. LONART ${ }^{\circledast}$ can be likened to a government that controls the prison yard. The judge discharges his sole responsibility by giving a verdict that keeps malarial fever in LONART's custody. In the guardianship of LONART malarial becomes inactive and ineffective. A sort of interchangeability is observed here. LONART is a custodian of the prison yard or it's the prison itself. Its duty is to imprison malarial fever in order to contain its excessive trauma on the people and make it redundant as a human prisoner. The judge is the intervening mechanism that empowers LONART to act and save the consumers from malaria fever sickness.

Sentence is salient and key in the text malaria remains sentenced in LONART custody. Sentence as a register from the usual judicial process is adopted to secure the message. It ends a judicial process. It is the finality of the process that indicates condemnation, conviction and doom. The indexical propagation of the judge is to issue a decree that lays to rest the negative function of malaria fever in human biological systems. The signifier (judge) signifies the end of an era, malaria fever trauma (signified) in any human being. The solution that LONART provides to the recipients is the signified in the plate. The advertiser of LONART criminalizes malaria fever and it is taken to the court of law to face a trial. The strategy is to assure that the audience of the quick response of LONART to exterminate malaria fever out of the body.

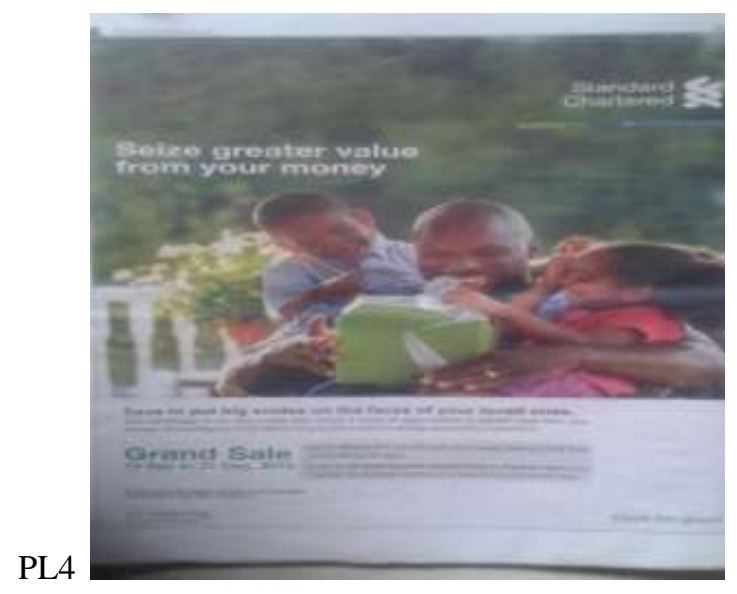

The signification in PL4 indicates the picture as the signifier which is an iconic representation of the signified, that is, family representation. The picture contains a father, a boy and a girl. Although the picture does not indicate a mother, it is still a family depiction. In a way, the picture signifies an ellipted family representation. A gift given to the children shows the existence of love among the family representatives. The bank, Standard Chartered ${ }^{\circledR}$ adopts a social reproduction of the key element, love that binds a family together to disseminate the ad's mission. The bank targets to connect the family to its service. It sensitizes the family by advocating seize greater value from your money. One needs to remember that the theme of Standard Chartered attempts to keep the savings of their customers. Financial strengths of customers are open to them. It is the savings kept in their charge that is the target of the bank. Customers are further enlightened in a better way to still utilize their savings, meaning that, those savings can still be channeled to something else in the bank for additional benefits. The approach advises consumers to retain about N100, 000.000 and above in their various accounts to benefit from the sales promotion.

The elliptical family pictorial representation designates the father and children in a very happy mood. It specifies to consumers the family situation expected if they participate in the on-going promotion. Then, the ad counsels thus: save to put big smiles on the faces of your loved ones. If customers retain N100, 000.000 for 30days or 90days respectively without a single withdrawal; this will qualify them to get iphone 6 and a trip to Paris for certain days. Promotional sales is an attempt to lure customers to be loyal to the bank by adopting socio-cultural norm (family desire) in the social system to sell the product.

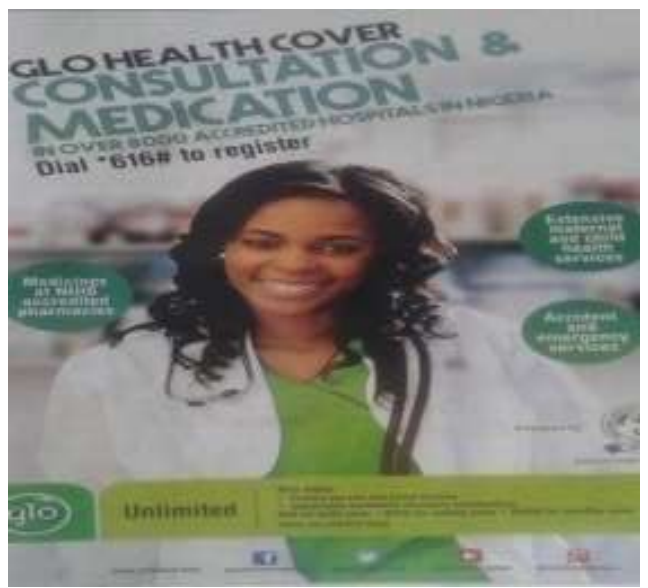


Advertisers are always looking for materials that can attract and convince the public of their mission. That is the reason for using materials that are not only charismatic but very simple and understandable which consumers can easily digest. Such a material is indexically presented in the Glo ${ }^{\circledR}$ ad in PL5. The ad shows a female medical doctor. Looking at a medical doctor in an ad signals health matters. Without reading the accomplished text, meanings are already created through the presentation of a woman with professional (medical) ware around her body. The bold picture of a womandoctor assists in the reduction of textual clusters and elements. The visual picture that even the illiterate can easily understand speaks volumes to the public. Notwithstanding, Glo health cover, Consultation and medication in over 8,000 accredited hospitals in Nigeria, and Dial $* 616 *$ to register give support to the signification of the picture of the woman-doctor.

In the organization of the ad frame, the picture is at the centre with short bursts of text surrounding the picture. It could be suggested that This is and with have been amputated from the clause so that it can be presented in pieces. With the suggested constituents, it should read: 'This is' Glo heath cover 'with' consultation and medication in over 8,000 accredited hospitals in Nigeria. The ad explains to the public the help that Glo renders to them and the extent that Glo can go in the provision of health facilities. The Glo medical assistance covers the provision of medicines, maternal and child health services, and accident and emergency services. The ad also typifies a daily payment of N35, a weekly payment of $N 250$ and a monthly payment of $N 1000$ for consumers who want to enjoy the services. The reproduction of a woman-doctor as a social element that the audience are conversant with symbolizes the intention of advertiser to make consumers understand the message as quickly as possible.

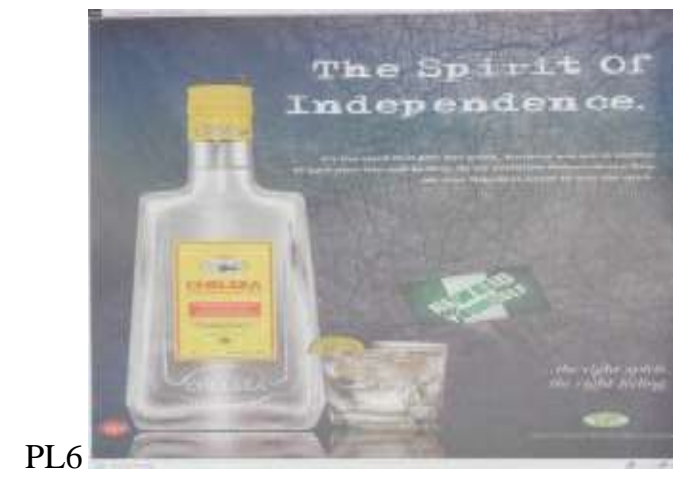

The situation of PL6 is a symbolic signification where a bottle is presented as Chelsea ${ }^{\circledR}$, and alcoholic drink. First and foremost, a bottle is a container, and any substance can fill it. The shape of a bottle sometimes, is not a true representation of its content. In another perspective, Chelsea as a name for an alcoholic drink is symbolic because in onomastics, any name can be created, coined or adopted to represent any thing (product) specially when such nomenclature does not violate social rules in any dimension. Chelsea is open to many contextual interpretations which include: (i) it is a distinct name in the Western London in United Kingdom; (ii) several places are named after London Chelsea in the United States of America; (iii) it is a female given name in London borough; and (iv) it is hard, white translucent material produced by fire. With this experience, Chelsea becomes a free concept that can be adopted to represent anything in the social system simply because of the popularity it portrays.

The bottle image of the alcoholic gin contains the inscription of Chelsea in the seal/cap, lower portion of the bottle and the label on the body of the bottle. The inscriptions are for the purpose of identification. A glass cup is also placed by its side containing orange-like and other elements. The placing of the glass cup by its side demonstrates the readiness of Chelsea alcoholic drink for consumption. The spirit of independence and reward yourself play a supportive role for the symbolic Chelsea image. The ambiguity of the term, spirit, promotes Chelsea from several vistas. It shows that Chelsea is a volatile alcoholic drink in the family of spirits. Given to the circumstance in which the Chelsea is campaigned, that is, the Nigerian Independence Day, spirit is remarkably phenomenal. It denotes the essence of independence, the style of its celebration (in which Chelsea is at the forefront), the aspirations of Nigerians during the Independence Day, the mental disposition and the audience minds' characteristics, and the intense feelings of all during the Independence. The impetus of Independence Day informs the advertiser to command the audience by saying that: reward yourself. The reward in the context refers to the enjoyment the drinking of Chelsea gin will provide consumers during the Independence Day celebration.

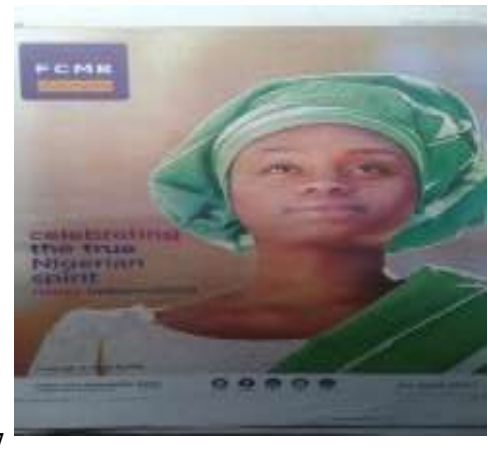


Contextualization of Yoruba attire propagates in PL7 the mission of First City Monumental Bank (FCMB). The image signification is iconic; it is a true photographic representation. Two elements signify Yorùbá-ness in the image, the first is the head tie and the second is the shawl placed on the shoulder of the lady. Both the head tie and shawl are in greenwhite-green which is the Nigeria color. It is an Independence Day ad that connects the people of Nigeria, Nigeria and FCMB $^{\circledR}$ together. The projection of the social event - Independence Day - is meant to effectively convince the public about the commitment of FCMB to the Nigerian people and Nigerian economic growth. The facial outlook of the Yorùbá lady suggests that FCMB which she represents sees a brighter future for Nigeria. The Yorùbá lady looks up afar to reveal her mental disposition about the future to the audience. In her outlook, she perceives the future as more important than the present. However, the present is a pointer to and bedrock of what the future holds for the people which could be the reason for celebrating the independence now as a reference to the future.

Two clauses - one independent (Celebrating the true Nigerian spirit), and two (Happy independence from all of us at $F C M B)$ are boldly inscribed in the frame. Despite that the later is not analyzable. It is a form of greeting from the FCMB team to all Nigerians. The ad inspires Nigerians to possess and celebrate the true Nigerian spirit. The revelation of the true Nigeria spirit is in the Nigerian National Anthem and National Pledge. Patriotism is the theme of the National Anthem. It covers commitment to the Nigerian project, love for one another irrespective of tribes and to harness the efforts of both the former and present leaders. The key element in the National Pledge is faithfulness that accommodates loyalty, honesty, honor and defense of the Nigerian nation. As a business enterprise, FCMB takes the advantage of the independence season to reach Nigerians and associate with the true Nigerian spirit - patriotism-cumfaithfulness. The socio-cultural reproduction is revealed in the Yorùbá-ness of the image, the National Anthem and Pledge in order promote Nigerian-ness in the social system.

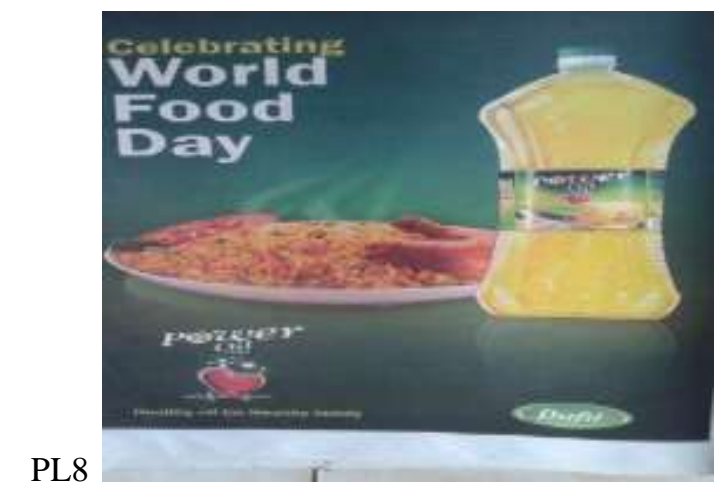

In PL 8, the Power Oil ${ }^{\circledR}$ ad demonstrates two images - a plate of food and a bottle of Power Oil - to illustrate its sociocultural alliance with the audience social conducts. From a semiotic reference, the plate of food is iconic while the container of Power Oil is symbolic. The plate of food is a picture can be identified without a label that it is food in essence, whereas the bottle of Power Oil is just a plastic container that corresponds to the label attached to it. Although the plastic container projects yellow color; yellow is not peculiar to Power Oil. Yellow can stand for any substance liquid or solid. There is a strong connection between the plate of food and Power Oil. Power Oil, as a cooking oil assists in food preparation and without which the palatability of the food might be unpleasant. The connection of the vegetable oil with food preparation is further demonstrated in the way the bottle of Power Oil romances with the plate of food.

The fragmented text, Celebrating World Food Day, is a means of partnering with the United Nations body that sees to the global hygienicity of human food consumption. Power Oil recognizes the World Food Day as a strategy to receive a reciprocating feedback from consumers. The association can be a global endorsement on the part of Power Oil that has the capacity to spur patronage. It seems that many consumers are ignorant of the historical World Food Day. The attempt of Power Oil advertiser to project an ad to commemorate that day is a plus; it enlightens consumers about its necessity. The matter of health is also projected through Power Oil ...healthy oil for healthy family. The approach is amazing. There are a number of vegetable oil packages in the market that harm human hearts and cause damages to human organs as the National Agency for Food and Drug Administration and Control (NAFDAC) usually campaigns. Healthy oil for healthy family indicates that Power Oil does not belong to that cadre; it rather sustains the health of the family. Sincerely, in all that we do, health is an important and considerable aspect that assists everyone to achieve success. That is the reason for Power Oil to associate with consumers' personal hygiene.

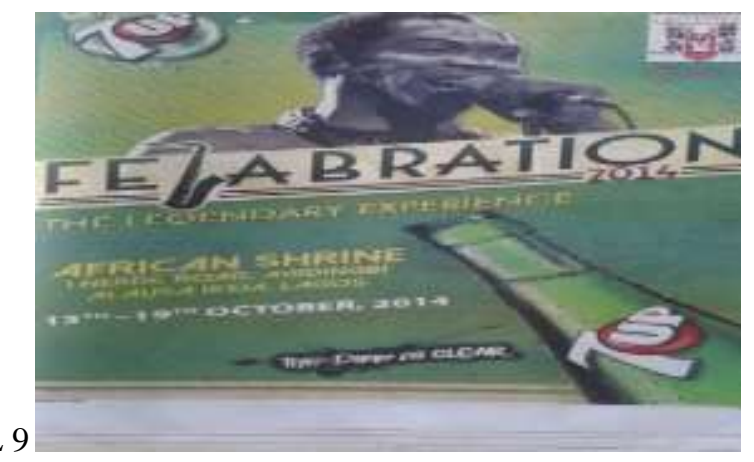


Fela's image is iconically characterized in PL9. As a global image, Fela is identified, among other things, with his halfnaked style and the efun (whitish chalk or lime) that marks his facial appearance. Apart from Fela's popularity, a set of microphones are in his hands to crystallize him more as an African, and by extension, world great musician. However, his fame overshadows the microphones. Another relevant image is the elliptical bottle of Seven Up ${ }^{\circledR}$ (7Up). Seven Up signification is symbolic. It is the label in the bottle that characterizes it as Seven Up soft drink. In a holistic signification, the signifier (Fela's picture) is iconic while Seven Up is symbolic in its signified.

Felabration 2015 supports the two signifiers - Fela's photograph and Seven Up. A morphological blending of lexicosemantic process contextualizes Felabration. Felabration is the combination of Fela + celebration, where cele, a part of celebration is cut off. The end formation of the linguistic surgical operation is Felabration. The process is recapitulated thus: Fela + 'bration $=$ Felabration. It explains the celebration of Fela's contributions to the social system. Such a legacy deserves to be remembered and celebrated. The ad further indicates the date, time and venue of Fela's festival. Seven-Up adopts this strategic accolade of Fela as an attempt to and a smart way of persuading Fela's followership. Fela's fans are further sensitized with the legendary experience for 7Up patronage.

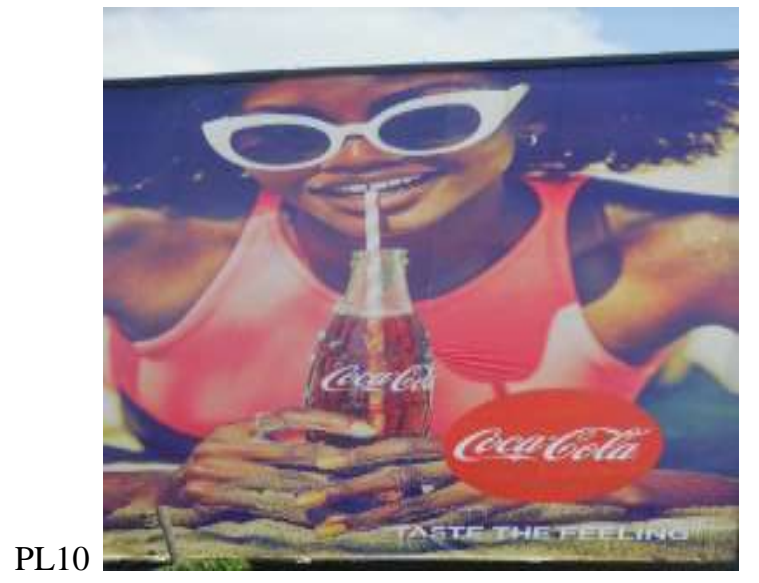

The semiotic illustrations in PL10 are obviously revealed in holistic manners. The Coca-Cola ${ }^{\circledR}$ (Coke: henceforth) ad demonstrates its semiotic holisticity in both the images and texts. A total signification is shown as red and white colors in both images and texts. Combinations of red and white colors connote the adopted color of Coke. As Coke usually appears in red-cum-white so also is the appearance of the photograph of the lady in an ordinary brassier and a pair of glasses. This kind of appearance relationship between Coke and the young lady can be suggested as iconic interchangeability. The picture is iconic for its resemblance of a lady whereas the Coke bottle is symbolic. Beside that most consumers are used to the shape of the Coke bottle, there is Coke emblem attached to it for further recognition. Perhaps, the content of the bottle could be something else if the bottle is not labeled with the Coke logo.

Five elements - the appearance of the lady, coke bottle, Coke logo, text and manner of drinking - signify the ad. The signifier, lady, demonstrates youthful dynamism expressed in exotic fashion. The Coke bottle is the product campaigns to consumers - the heart of the ad and its message. It can be simply addressed as the essence of the ad. The Coke logo is a zeal that identifies and establishes its authority over the soft drink market realm. The text, taste the feeling, supports the manner in which the lady is zipping Coke. Taste the feeling, can perhaps be explicated in two domains: to taste the beautiful lady for a particular feeling (love) associated to lovers; or to taste Coke for such a feeling that the lady enjoys while drinking Coke. Feeling is further observed in a peculiar and relaxation technique that the lady holds the Coke bottle tightly with her two hands in a similar method that a man holds a woman despite Coke's chilled appearance. The audience can reciprocate the same to the fashionable lady as to Coke. The coldness of the Coke bottle radiates the lady's hands, yet, she drinks laughingly with excitement as if there are no negative biological feelings. In all, the socio-cultural reproduction displays exuberant youthfulness, exotic fashion and exchanging love as side attractions and persuasion.

\section{Conclusion}

Advertisers and ads are somehow close to the society. The closeness is not at all a voluntary one but the intention of advertisers' ads compels them to fall prey, prostrate and surrender to elements in the social system. Socio-cultural activities in ads serve an endless purpose of association with the society, although the social actors are not sometimes interested in the ad campaigns. Advertisers see socio-cultural items as instruments that can convince and induce the society to give audience to the messages of ads. However, we need to appreciate advertisers' efforts in search of captivating social devices in order to convince the public. The items in the ads link the recipients to the social elements and consumers to the products advertised. Ads also provide understanding of our cultural heritage and their locations of, for instance, terracotta to the public. Advertising propagated in such a height has the muscles to motivate the governments - federal, state and local - to pick interest in terracotta and other socio-cultural items and preserve them. By implication, the study demonstrates that socio-cultural reproduction in ads has the capacity to attract tourists into the country for national development and economic growth. In addition, it serves as a source of entertainment to the entire public who are consumers of ads. We suggest that government should encourage the production of ads associated with socio-cultural elements not only with supportive policy promulgation but also in financial participatory regimen. Therefore, as it has become increasingly difficult to separate consumers from their cultural heritage, consumption of goods and services can skyrocket if elements of culture are consistently featured in ad plates. 


\section{References}

Awonusi, V. O. (2007) Invitation as Style and Discourse in Nigerian English. Literature and Language; A Drama of Life: A Festschrift in Honour of Z. A. Adejumo, 86 - 97.

Bathes, R. ([1957]1987). Mythologies. New York: Hill \& Wang.

Bathes, R. ([1964]1967). Elements of Semiology. (Trans. Annette L. \& Colin S.). London: Jonathan Cape.

Beck, U. \& Beck-Gernsheim, E. (1996). Individualization and 'precarious freedoms': Perspectives and controversies of a subject-oriented Sociology. In Healas, P., Lash, S., \& Morris, P. (Eds.), Detraditionalization (pp. 23-48). Oxford: Blackwell.

Blommaert, J. (2009). Discourse. Cambridge: Cambridge University Press.

Bloor, T. \& Bloor, M. (2004). The functional analysis of English. Great Britain: Hodder Arnold.

De Beaugrande, R. (1991). Linguistic theory: The discourse of fundamental works. London and New York: Longman.

Dyer, G. (2005) Advertising as communication. London: Routledge.

Eco, U. (1976). A theory of Semiotics. London: Macmillan.

Goldman, R. (1992). Reading ads socially. London and New York: Routledge.

Halliday, M. A K. (1994). An Introduction to functional grammar. Great Britain: Arnold.

Halliday, M.A.K. \& Matthiessen M. I. M. (2004). An introduction to functional grammar. Great Britain: Hodder Arnold.

Hodge, R. \& Kress, G. (1988). Social semiotics. Cambridge: Polity.

Jakobson, R. (2006). Linguistics and poetics. In Jaworski, A. \& Coupland, N. (Eds.), The discourse reader (2 $2^{\text {nd }}$ ed., pp. 48-54). Routledge: New York.

Jaworski, A. \& Coupland, N. (eds.) (1999). The Discourse Reader. London/New York: Routledge.

Lemke, J. L. (1995). Textual politics: Discourse and social dynamics. Oxon: Taylor \& Francis.

Luhmann, N. (1996). Complexity, structural contingences and value conflicts. In Healas, P., Lash, S., \& Morris, P. (Eds.), Detraditionalization (pp. 72-86). Oxford: Blackwell.

Peirce, S. (1931-58). Collected writings (8 vols.). Charles, H., Weiss, P. \& Burkes, A. [Eds.]). Cambridge, MA: Harvard University Press.

Ravelli, L. (2000). Getting started with functional analysis of texts. Researching Language in schools and communities, $1,27-63$.

Schegloff, E. (2006). Talk and social structure. In Jaworski, A. \& Coupland, N. (Eds.), The discourse reader ( $2^{\text {nd }}$ ed.), pp. 86-97. Routledge: New York.

Thompson, G. (2004). Introducing functional grammar. Great Britain: Hodder Arnold.

Van Dijk, T. A. (1998). Ideology: A multidisciplinary approach. California: SAGE Publications Inc.

Williamson, J. (1978). Decoding advertising: Ideology and meaning in advertising. New York: Marion Boyars.

\section{Internet Resources}

Chandler, D. (2006), Media Semiotics. Retrieved from http://www.scribd.com/doc/205815385/14165439-Media-

Representation- David-handler\#scribd

Halliday, M.A.K. \& Matthiessen, C.I.M. (1997). SFT: A first step into the theory. Retrieved from http://web.uam.es/departamentos/filoyletras/filoinglesa/Courses/LFC- SFL/FirstStep.html

Hébert, L. (2011). The Functions of Language. Retrieved from https://www.scribd.com/document/212412352/FUNCTIONS-of-LANGUAGE-L-Hebert http://www.dipartimentolingue.unito.it/herrmann/documents/

Sells, P. \& Gonzalez S. (2002). The Language of Advertising. Retrieved from http://www.york.ac.uk/language/staff/academic-research/peter-sells, 21 August 2012 